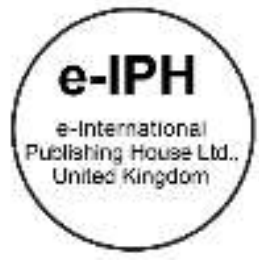

\title{
The Internationalisation of Online Video Content Industry: An analysis of the behaviour of consumers and content providers
}

\author{
Herwina Rosnan ${ }^{1}$, Nuraisyah Chua Abdullah² \\ ${ }^{1}$ Arshad Ayub Graduate Business School \\ 2 Faculty of Law, \\ Universiti Teknologi MARA, 40450 Shah Alam Selangor, Malaysia \\ herwinaros@gmail.com, nuraisyahc@yahoo.com,nuraisyah@salam.uitm.edu.my \\ Tel: +60192345680
}

\begin{abstract}
Global online video content has received great demand worldwide. This Internet platform provides consumers with the liberty to choose what, when and how they want to view film content. The concern is on whether the new trend affects the behaviour of local consumers and local content providers. Hence, the primary objective of this paper is to investigate how consumer preferences are altered and how consumers' new preferences affect local businesses. Primary data through the interview with selected local content providers and secondary data were collected and analysed. The findings show that the traditional, as well as online content providers, are affected by the internationalisation of this industry.
\end{abstract}

Keywords: Online Video Content; Global Content Industry; Consumer's Behaviour, Content Providers' Behaviour

eISSN: 2398-4287 @ 2018. The Authors. Published for AMER ABRA cE-Bs by e-International Publishing House, Ltd., UK. This is an open-access article under the CC BYNC-ND license (http://creativecommons.org/licenses/by-nc-nd/4.0/). Peer-review under responsibility of AMER (Association of Malaysian Environment-Behaviour Researchers), ABRA (Association of Behavioural Researchers on Asians) and cE-Bs (Centre for Environment-Behaviour Studies), Faculty of Architecture, Planning \& Surveying, Universiti Teknologi MARA, Malaysia.

DOI: https://doi.org/10.21834/e-bpj.v3i8.1407

\subsection{Introduction}

Online video content is a film content or known as video on demand (VOD) that use Internet platform for online video streaming. Film content has become a global business as these film contents are available whenever there is Internet infrastructure. Today, there is a growing demand for global content in online video streaming. Global content receives high popularity and great demand worldwide in online video streaming industry. For over two decades, video streaming over the Internet has received a substantial amount of attention from both academia and industry. The local content (films related products) are able to attract millions of audiences. In Malaysia, although the internet users who watch online video content has increased to around 70 percent, and it was forecasted that the internet video market would increase fourfold by 2019 , the concern is on whether the benefit goes to foreign film players as global players are associated with vast resources and better able to compete compared to local film companies. These opportunities contribute the positive impact to local content providers to chart international market.

The drivers behind the dynamic change of content industry are due to shifting preferences amongst consumers in television operating system from physical cable television to online video content. This resulted in the options for consumers who have an array of choices concerning online video content which incurred meagre switching costs. In 2017, Tonton (a subsidiary under Media Prima Group which is one of the leading players in the broadcasting industry in Malaysia) was still struggling to reach large customer segments. This is due to the entrance of Netflix (a U.S based company) in 2016 which affected the financial performance of Tonton. Tonton's revenue decreased sharply in 2016 to merely RM2.3 million in 2015 compared to RM11.3 million revenues in 2015. Although Netflix subscription is higher than Tonton, but Netflix is more favourable to the consumer as they hold global content (foreign films related products).

eISSN: 2398-4287 @ 2018. The Authors. Published for AMER ABRA cE-Bs by e-International Publishing House, Ltd., UK. This is an open-access article under the CC BYNC-ND license (http://creativecommons.org/licenses/by-nc-nd/4.0/). Peer-review under responsibility of AMER (Association of Malaysian Environment-Behaviour Researchers), ABRA (Association of Behavioural Researchers on Asians) and cE-Bs (Centre for Environment-Behaviour Studies), Faculty of Architecture, Planning \& Surveying, Universiti Teknologi MARA, Malaysia.

DOI: https://doi.org/10.21834/e-bpj.v3i8.1407 
Today, global content/film receives high popularity and high demand worldwide in online video streaming industry. This trend brings about advantages and challenges to the local industry. On the one hand, this new trend enables the consumers to enjoy an array of choices concerning online video content at a lower price and with lower switching costs. Besides, through online video content, the local film like JRevolusi and Cicakman were able to attract millions of audiences worldwide. However, on the other hand, the local industry is easily penetrated by global players as this industry has low entry barrier and this increase competition which affect the performance of a local company. For example, since Netflix (a U.S-based company) arrived in Malaysia in 2016, the revenue of Tonton (a local company under Media Prima) decreased sharply to merely RM2.3 million from RM11.3 million in 2015. Globalization and liberalisation were argued to bring about the benefit to the well-being of a nation. In Malaysia, although the internet users who watch online video content has increased to around 70 percent, and it was forecasted that the internet video market would increase fourfold by 2019 , the concern is on whether the benefit goes to foreign film players as global players are associated with vast resources and better able to compete compared to local film companies. Hence, the primary objective of this paper is to investigate how technology alters consumer preferences and how consumers' new choices affect local content service providers namely traditional and local online content providers.

\subsection{Tonton: Main Video Portal in Malaysia}

In early 2010, Media Prima realised a strong evolution trend in the broadcasting industry. Fast internet connection has changed consumer lifestyles and preferences towards television programmes selections. Malaysians do not watch television for daily entertainment; instead, they are selective about what they watch which include important news few movies or drama available during a limited period of time. Consumers searched for essential online video purchase, or view an online programme which is freely available. YouTube has become the most attractive online video streaming that become the substitute and rivals to video rental stores, television cables and another small player firms which offer online services. Tonton which was created to catch up service for Media Prima's terrestrial television stations' program is the most appropriate tool to use to respond to the current trend in online video streaming. Media Prima has been aggressively promoting Tonton as local online video content platform under Media Prima Digital. However, due to stiff competition from global content in 20017 , Tonton performance was lag behind its foreign competitors.

Media Prima found that consumers are indeed looking for some good film and movies in which they often search for several sources from the websites and are looking for sources that can offer attractive and cheaper price. Additionally, Media Prima found that the switching costs to online content are more economical and the availability of substitutes are enticing to customers. Taking that into consideration, Media Prima believe that local online video content is still relevant in the Malaysian market. In Malaysia, there are few local companies offer online video streaming. They are [1] Tonton, [2] Iflix, [3] Viu, [4] Dim Sum and [5] HyppTV. However, concerning market share, Tonton is leading and was the first video portal provider which started with Advertising Video On Demand (AVOD) established in 2010 and transformed itself into a hybrid video service in 2016 which is now called Tonton VIP. Internet media platform enables Tonton to reach the foreign market at lower cost with minimum cross-border barriers. Apart from that, Tonton also involved in an international licensing agreement to acquire different video content from Indonesia, the Philippines, Korea, China and Europe. The principal competitive advantages of Tonton are the packages offered are attractively priced compared to its competition which is merely RM3 per day and RM10 per month. It provides original local content, giving it a unique positioning not matched by other players in a local market. In most cases, Tonton is preferred by Malaysians who lived in foreign countries to access to domestic programs like Majalah 3, Akasia and Bulletin Utama. However, in early 2016, the arrival of Netflix has challenged Tonton position in the local market.

\subsection{Netflix: A Rival}

Netflix, a U.S based company, has been in online video streaming industry for 20 years since 1997 and gained strong market position compared to its competitors Hulu and Amazon Prime Instant Video in the U.S market. Tonton realised that it lacks the capability to compete with Netflix which is a giant global player which has dominated many markets worldwide. In order to compete, Tonton has to understand Netflix's business model. Indeed, Netflix has the ability to offer a much lower price. Netflix provides unlimited subscriptions for merely USD7.99 a month or RM33.60 a month. Apart from that, Netflix contents are mostly global content from established film industry like the Hollywood. These include contents/programmes from Disney Channel, Starz, Sony/Columbia Pictures, 20th Century Fox, Universal Studios, HBO and Warner Bros. Apparently, Netflix business requires high capital investment to enable them to secure high-quality online video contents which are very highly priced. In this industry, the bargaining power of the suppliers (film produces) is high as there are few mainstream suppliers in the global market.

Netflix, on the other hand, is struggling with operating cost which includes salaries, marketing expenses and other operational costs to run online video service. Success is highly dependent on whether Netflix would be able to secure video contents which are highly preferred by the audiences. Nonetheless, in light of ever-changing technologies and the advancement in the broadcasting industry, Tonton believes that there is still an avenue to differentiate Tonton from foreign global players.

Video on demand works through Real Time Streaming Protocol (RTSP) where viewers can choose their preferred audio-visual content which is then transmitted to them in real time. The system allows viewers to watch film/video content using their smart television or computers (Technopedia, 2018). There are many videos on demand providers in the global market as this new industry has a low barrier to entry. Reuters (2013) reported that Netflix is the most popular video on demand subscription-based provider and globally it operates in more than 40 countries. Netflix is a monthly-based subscription video on demand service provider. In 2013, there were 35.7 million Netflix subscribers in U.S market alone, and Netflix is ambitious to internationalise and capture the global market. The trend towards video on demand is an indication of how it would affect industry like cinema and television broadcasting. 


\subsection{Literature Review}

Globally, the introduction of online video streaming has changed the dynamic of consumer viewing, and the preferences have shifted from tradition television viewing and cinema going to Internet streaming. A study in the United Kingdom revealed that the number of viewers who watch television through "Video-On-Demand" services is experiencing a steady increase with 26 per cent of viewers' watch television through on-demand services compared to conventional television linear (YouGov, 2012). Besides, viewers who own a smart TV that can be connected to the internet spent 35 percent of their weekly television viewing by watching television using on-demand services (YouGov, 2012).

In the U.S, the number of viewers that watch television through Internet streaming video has risen since the 1990s. According to a study by Wu (2013) on average, the U.S viewer consumes five hours of TV every day, in a week these viewers spent 45 minutes of their television viewing per week on Internet streaming video. The introduction of Netflix, an online video content provider in the U.S market, has increased the number of viewers who prefer online video streaming as it can distribute film/video content based on consumers' preferences. Netflix is targeting individual needs and preferences, unlike the cinema model which target is the mass market (Wu, 2013). Furthermore, online video streaming can be watched anywhere and anytime based on individual preference. Netflix is not only providing online video content, but it also produces its video content/programmes that competes directly with cinema or traditional television content. This competitive advantage created by online video content provider, enable them to capture the market of conventional television viewers.

In Ireland, with the emergent of online video streaming, consumers are no longer have to chain themselves in front of the television to follow television scheduling, but instead online video streaming gives them the liberty to choose when and how they access entertainment content. A report by The Sunday Business Post (July 22nd, 2013) showed that there are over 70,000 Netflix subscriptions in Ireland indicating the popularity of online video content. As of end March 2013, Commission for Communications Regulation (2013) reported that the number of active internet subscriptions in Ireland was 1.68 million subscribers. This is a positive indication of a new market in which online video content provider or video on demand (VOD) service provider has potential to grow its market share.

In 2014, PricewaterhouseCoopers conducted studies in which the findings revealed that online video streaming and film downloading will overtake the traditional cinema by 2017 . The current total film revenue in the U.S valued at $\$ 8.5$ billion, and it is expected that online video streaming alone will contribute to total film revenue with an estimation of $\$ 17$ billion in 2017 which will be the most significant contributor to the U.S film industry. According to PwC Global Entertainment and Media Outlook 2014-2018, online video content would be the most significant contributor to total film revenue in the US reaching a total of $\$ 17$ billion the following year. (PricewaterhouseCoopers, 2014).

The rise of new Internet Communications Technologies (ICT) that created as video on demand services and an evolving broadband infrastructure has provided the opportunity to consumers to choose what they want to view when they want to watch, and on what device they prefer to watch video content (Tryon 2013). The development of physical and non-physical infrastructure enables online video streaming services to flourish. Now, the industry has given the consumer more bargaining power that they decide what they want to view. It has shortened the window period between film release and the availability of the same film to be downloaded. Because of this, traditional cinema is affected as they are losing competitive advantage to this new market. Besides, online content providers like Netflix, Amazon Instant Video, and Hulu have captured the market as they are also a creator of original content (Tryon, 2013). Netflix, for example, spends millions to create their own film content ( $\mathrm{Wu}, 2013)$. The dynamic change in the film industry has turned the middleman into the creator of film content which Tryon (2013) termed it as from "mere middlemen to creators of original content". In particular, the film industry has witnessed the emergence of Netflix that has paved the way and become a successful producer and distributor of original film content. According to a report by Pricewaterhouse in the first quarter of 2014, Netflix experiences an increase in revenue of 24 per cent.

Tryon (2013) termed this new phenomenon as a democratisation of media in which the power has shifted to consumers concerning how audio-visual entertainment content is viewed. Now, the consumer has the liberty to choose what they want to watch, when to watch and how they want to experience the film or video content. This online Internet content service has removed the need to wait for scheduled content and gives freedom to consumers to enjoy their entertainment options.

It can be summarised from the review of previous studies that the trends in film viewing have moved from traditional television broadcast and cinema viewing to online film viewing and film downloading. The online content providers have created a competitive advantage over their traditional television and cinema rivals. However, study by Tryon (2013) on the impact of online content provider towards cinema businesses suggested otherwise. When asked whether their business is affected by the new trend in Internet and online video streaming, the managers expressed little concern over online film service providers. According to the managers, the real threat comes from online and video piracy rather than subscription-based business model introduced by online content providers.

Cinema and television broadcast companies are responding to the trend towards video on demand by altering their offerings. As cinema can no longer capture mass market viewers, it has changed the way consumer experience cinema entertainment by targeting at the niche market and redesigning cinema facilities and infrastructure that suit the niche demand. Subsequently, traditional television has also entered into serving consumers with online video content by adopting both online and offline business model.

\subsection{Methodology}

This study is exploratory research which data were collected from both primary and secondary sources. Primary data was gained through the interview with content providers. This is to gain an in-depth understanding of how industry players respond to the current trend of the internationalisation of online video content which brings about competition into local online video content industry. A descriptive 
analysis was conducted to achieve the objectives of the research. Data from the transcripts were analysed by looking at the information to derive major ideas addressed for this researched. The content analysis of secondary data indicates the response of the consumers and how their response affect the industry. The secondary sources include published articles, past research papers as well as newspapers article.

\subsection{Findings and Discussion}

Online video content has particularly enticed the younger generation, and the consumption of film content has significantly altered the way the younger generation experience audio-visual content. Consumers are now preferred to spend their time online or through mobile device or computing device or smart television as opposed to watching movies through conventional means. The rapid adoption of technology has evolved and created a new film distribution channel. The new phenomenon in film consumption is evidence of the changing consumers' behaviour and created consumers who are independent of traditional television scheduling and create the need for individualisation. Amazon was the first software provider that come up with new technology allowing individualisation. The software was then used as a platform to view online video content. Tryon (2013) termed the new phenomenon as the "democratisation of media" where the new technology support personalisation of service and a higher degree of choice. Although factors like download speeds and cost of broadband data might hinder the development of online video content, with the improvement of Internet infrastructure, this industry provides vast opportunities for online content providers.

A provider like Netflix is fast and pro-active in capturing the opportunities in the market by creating software that enables the company to profile consumers film tastes and preference (Madrigal, 2014). This is the strategy used by Netflix that allows it to reverse-engineered Hollywood film industry. Netflix invested a substantial amount of money in developing teams that could electronically tag consumers on their preferred movies. Like Amazon, the software serves up suggestions based on consumers' profile on the previous viewing.

Internet and the advancement of technology led to qualitative changes in the film industry over the last decades. Netflix is the main competitor to local players which has affected the performance of local player very severely. It has been challenging the position of local players. Tonton experienced a lower number of subscribers that lead to poor financial performance for the first nine months of 2016. Tonton performed better for the past few years because Malaysians were not familiar with online video content. Comparatively, Netflix was priced higher than Tonton, but it can still capture the market as it offers a more attractive package. Tonton depends heavily from local content like Grand Brilliance, KRU Studios, Skop Productions Sdn. Bhd., Excellence Pictures Sdn. Bhd., The Film Engine Sdn. Bhd. and Tayangan Unggul Sdn. Bhd. Consequently, price strategy, i.e. offering a lower price than the competitor is not a success formula.

The key strengths of Tonton come from its large library titles of local contents because most of the production houses/companies sell their content to Tonton. Local contents are not readily available to foreign television broadcasting, and that is a competitive advantage for Tonton as it serves the niche market of Malay population and diaspora. Besides, Currently, Tonton's subscription-based is 7.3 million subscribers and is the highest by local standard. Tonton also has a strong existing network of integrated promotion and marketing channel due to high brand image and reputation. Most importantly, Tonton has its own in-house production house namely Primeworks and Global Brilliance.

However, Tonton contents are predominately Malay contents using Malay language. The market for Malaysian contents is globally limited. Apart from that, local contents are subject to the approval of censorship board and government regulations. Indecent contents are restricted in Malaysia. Globally, those are the contents that received higher rating and demand. Local producers and companies lack the ability to produce quality contents as they have limited fund. Generally, its contents are incomparable with global contents.

One of the opportunities for Tonton is to tap on the existing rights to air local sports events. Tonton has live television to broadcast highly watch programs like Piala FA Malaysia and Jom Heboh. Global diaspora is the market tapped by Tonton and other local video content providers.

Currently, merger and acquisition are prevalent in online video streaming industry, particularly among international media companies. The liberalisation of service and broadcasting industry posed a threat to local players like Tonton. In addition, the biggest threat to local online video provider is internet piracy. Piracy in online video content is way more accessible, and many websites are offering similar titles with way lower price. Furthermore, it is not easy to track down piracy as they could be anywhere in this world.

Despite the positive trend in online video content industry, its primary issue is concerning illegal content downloading. Online piracy is a global issue for the online content provider with limited ways to control it. In addition, online business has commonly is a low entry barrier industry with competitors coming in with low transaction cost. On the part of consumers, low switching costs is also a challenge for online content providers. The future might prove an intense competition among online content providers. The role of government is vital in ensuring the consumers and businesses are well-taken care of.

\subsection{Conclusion and Implication}

Netflix is using sophisticated software to track consumer tastes and preferences in an effort to serve up suggestions to customers (Madrigal, 2014). Netflix has also employed teams to view content and electronically tag the content type in an attempt to create a list of genres and sub-genres. This painstaking process has led to the creation of over 76,000 genres. This enables users to search for specific content and also serves up suggestions to users based on their previous viewing preferences. According to Yellin, VP of new product innovation and designer of the genre system "the better Netflix shows that it knows you, the likelier you are to stick around". He adds that the 37 aim of Netflix is to attract and retain customers and that by employing this system to serve up recommendations the 
company will achieve this (Madrigal, 2014). The film industry is set to gain from this trend towards digital entertainment consumption as it provides another channel for consumers to purchase their offerings. However, the VOD providers such as Netflix, Amazon Prime, and Hulu are evolving their strategies. Until recently they were merely distributors of digital content but have now become content producers (Tryon 2013). They have moved from being middlemen to the movie industry towards producing and distributing their own TV shows such as House of Cards and Orange is the New Black. This strategy has allowed them to regain an element of control and attain a competitive advantage versus the cinema.

The cinema industry at present does not support screen TV series. The findings show that the television and broadcasting sector is very much affected by globalisation. Companies like Media Prima Berhad, Astro and RTM, have to rationalise their business model to respond to current pressure and new preference by the audience. Consumer behaviour keeps on changing, and it has altered the way business is done. This study contributes to enhancing understanding of the effects of globalisation on local consumers and content providers that provide an avenue for policy-makers to respond to this new trend.

\section{Acknowledgements}

The authors would gratefully acknowledge the Institute of Research Management and Innovation (IRMI) Universiti Teknologi MARA (UiTM), Shah Alam and Ministry of Higher Education Malaysia (MOHE) for the financial support through the Fundamental Research Grant Scheme, File No: 600-IRMI/FRGS 55/3(36/2015).

\section{References}

Abdel-Hadi, A. (2012). Culture, quality of life, globalization and beyond. Procedia-Social and Behavioral Sciences, 50, 11-19.

Abdullah, J. (2012). City competitiveness and urban sprawl: Their implications to socio-economic and cultural life in Malaysian cities. Procedia-Social and Behavioral Sciences, 50, 20-29.

Commission for Communications Regulation. (2013). Quarterly key data report data as of Q1 2013, [online] Available from http://www.comreg.ie/_fileupload/publications. Last accessed 25th November 2017.

Ma, W. (2017). Mobile entertainment. China's Mobile Economy: Opportunities in the Largest and Fastest Information Consumption Boom, $159-188$.

Madrigal, A. (2014). How Netflix Reverse Engineered Hollywood. Available: http://www.theatlantic.com/technology/archive/2014/01/how-netflix-reverseengineeredhollywood/282679/.

Oktay, D. (2012). Human sustainable urbanism: In pursuit of ecological and social-cultural sustainability. Procedia-Social and Behavioral Sciences, 36, 16-27.

Orbach, B. Y., Einav, L, 2007, Uniform prices for differentiated goods: The case of the movie-theatre industry, International Review of Law \& Economics.O'Regan, T. (2000). The End of Cinema? The Return of Cinema? Metro. 124/125 (11), 64.

Panitchpakdi, K. (2012). The Sustainability of Local Community under the Globalization: The Case of Kao Yi Sarn, Samutsongkram, Thailand. Procedia-Social and Behavioral Sciences, 36, 361-371.

PricewaterhouseCooper. (2014). Global Media and Entertainment Outlook 2014-2018. Available: http://www.pwc.com/gx/en/global-entertainment-mediaoutlook/datainsights.jhtml. Last accessed 10th Jan 2018.

Techopedia. (2013). Video on Demand (VOD). Available: http://www.techopedia.com/definition/25650/video-on-demand-vod. Last accessed $11^{\text {th }}$ December 2017.

Tryon, C (2013). On-Demand Culture - Digital Delivery and the Future of Movies. USA: Rutgers University Press. 1-117.

Wu, T. (2013). Netflix's War on Mass Culture. Available: http://www.newrepublic.com/article/115687/netflixs-war-mass-culture. Last accessed $9^{\text {th }}$ December 2017.

YouGov. (2012). Majority of TV Viewing now "On - Demand" for 1 in 4 Brits. Available: http://cdn.yougov.com/cumulus_uploads/document/j8hi9ko29n/Smart\%20TV\%20\%20\%20Consumer\%20PR\%20\%28FINAL\%29.pdf. Last accessed 11th December 2017.

Yusof, F., Abdullah, F., Hussain, M. Y., \& Selvadurai, S. (2012). Connecting to the Global Circuit: Matching the Learning Cities of South-East Asia as the Preferential Place for Global Corporate Innovation Culture. Procedia-Social and Behavioral Sciences, 36, 221-234.

Yusof, J. M., Manan, H. A., Karim, N. A., \& Kassim, N. A. M. (2015). Customer's Loyalty effects of CSR Initiatives. Procedia-Social and Behavioral Sciences, 170, 109119. 